\title{
PORPHYROMONAS GINGIVALIS E PERIODONTITE CRÔNICA - AVANÇOS RECENTES
}

\author{
Victor Hugo Rocha Leon*, Ellen Karla Nobre dos Santos Lima**, Ana Carla Montino Pimentel***, \\ Patrícia Mares de Miranda****, Paulo Cirino de Carvalho Filho*****, Soraya Castro Trindade******, \\ Márcia Tosta Xavier \\ Autor correspondente: Ellen Karla Nobre dos Santos Lima - ellenobre@hotmail.com \\ * Cirurgião-dentista \\ ** Cirurgiã-dentista. Doutoranda em Imunologia, Universidade Federal da Bahia \\ *** Periodontista. Doutoranda em Imunologia, Universidade Federal da Bahia \\ **** Cirurgiã-dentista. Mestranda em Imunologia, Universidade Federal da Bahia \\ ***** Doutor em Imunologia. Professor Assistente da Escola Bahiana de Medicina e Saúde Pública \\ ****** Doutora em Imunologia. Professora Titular da Universidade Estadual de Feira de Santana \\ ******* Doutora em Bioquímica. Professora Adjunta da Escola Bahiana de Medicina e Saúde Pública
}

\section{Resumo}

A periodontite é multifatorial e acomete os tecidos circundantes dos dentes. Sua etiologia inclui microrganismos como Porphyromonas gingivalis, Tannerella forsythia e Aggregatibacter actinomycetemcomitans. Este trabalho objetivou discutir o papel de Porphyromonas gingivalis na periodontite crônica. Foram pesquisadas as bases eletrônicas PubMed, BIREME e SciELO, buscando aspectos históricos e estudos publicados entre 2000 e 2015 , usando, em português e inglês, os descritores: "Periodontite Crônica", "Porphyromonas gingivalis" e "Fatores de virulência". Foram encontrados 205 artigos e 24 foram incluídos. Foram selecionados registros sobre doenças periodontais dos primórdios civilizatórios até os dias atuais. Sua prevalência na população mundial permanece alta e diversas pesquisas abordam a etiopatogenia da doença. $P$. gingivalis é capaz de induzir resposta humoral e celular nos indivíduos infectados. Estudos sobre seus mecanismos de escape e fatores de virulência relatam dano tecidual consequente à resposta imuno-inflamatória exacerbada do hospedeiro que pode evoluir para edentulismo. Estudos da resposta imune a $P$. gingivalis sugerem seu papel na perpetuação do estado inflamatório por interferir na produção de citocinas e em mecanismos de morte celular em tecidos do hospedeiro, resultando em destruição tecidual. Os conhecimentos atuais sobre mecanismos de infecção e fatores de virulência de $P$. gingivalis indicam seu papel como componente-chave na periodontite crônica.

Palavras-chave: Periodontite Crônica; Porphyromonas gingivalis; Fatores de Virulência. 


\title{
PORPHYROMONAS GINGIVALIS AND CHRONIC PERIODONTITIS - RECENT ADVANCES
}

\begin{abstract}
Periodontal disease is multifactorial and it affects the tissues surrounding the teeth. Its etiology includes microrganisms as Porphyromonas gingivalis, Tannerella forsythia and Aggregatibacter actinomycetemcomitans. This work aimed to discuss the role of Porphyromonas gingivalis in chronic periodontitis. The electronic bases PubMed, BIREME and SciELO were used to search for historical aspects and studies published between 2000 and 2015 , using the following descriptors in Portuguese and English: "Chronic periodontitis", "Porphyromonas gingivalis" and "Virulence factors". 205 articles were found and 24 were included. Records on periodontal diseases from the early civilization to the present day were found. Its prevalence in the world's population remains high and several studies report the pathogenesis of the disease. P. gingivalis is able to induce humoral and cellular response in infected individuals. Studies on its escape mechanisms and virulence factors report tissue breakdown due to the immuno-inflammatory exacerbated response in the host which may evolve into edentulism. Studies of the immune response to $P$. gingivalis suggest its role in perpetuation of the inflammatory state by interfering with cytokines production and cell death mechanisms in the host's cells, resulting in tissue destruction. The current knowledge about mechanisms of infection and virulence factors of $P$. gingivalis indicates its role as a key component in chronic periodontitis.
\end{abstract}

Keywords: Chronic Periodontitis; Porphyromonas gingivalis; Virulence Factors.

\section{INTRODUÇÃO}

A doença periodontal ocorre devido a uma relação entre infecção por microrganismos, localizados no biofilme supra e subgengival, e as respostas inflamatórias por parte do hospedeiro. A presença de bactérias no biofilme e seus componentes produzidos durante a colonização são os maiores responsáveis por desencadear a resposta inflamatória. Esta resposta, com propósito inicial de proteção, acaba por destruir os tecidos periodontais de suporte à medida que vários mediadores inflamatórios são sintetizados e liberados. Ao exame clínico de indivíduos com periodontite, é possível observar rubor, sangramento, edema, retração gengival, perda de inserção clínica, presença de secreção purulenta e bolsas periodontais; podendo ocorrer recessão gengival; mobilidade, migração e perda dentária.( ${ }^{(1)}$
Estudos comprovam uma associação entre as bactérias Porphyromonas gingivalis, Aggregatibacter actinomycetemcomitans, Tannerella forshytia $e$ Treponema denticola, relacionando-as como principais patógenos ligados à progressão e à gravidade da periodontite. Essas bactérias estão mais profundamente instaladas nas bolsas periodontais, sendo encontrada uma maior concentração de $P$. gingivalis nas amostras analisadas. ${ }^{(2)}$

Componentes de $P$. gingivalis modulam a resposta imune do hospedeiro por meio de indução de apoptose de linfócitos $\mathrm{T}$ e macrófagos. Além disso, esses componentes moleculares promovem a liberação de citocinas pró-inflamatórias. (3) Tais fatores de virulência podem estimular a liberação dessas citocinas, que, além de intensificar a res- 
posta inflamatória, aumentam a produção de metaloproteinases da matriz, resultando na degradação do tecido conjuntivo e na reabsorção do osso alveolar por indução de atividade descompensada de osteoclastos. ${ }^{(4,5)}$

Sabendo-se da influência de $P$. gingivalis na doença periodontal e que seus constituintes têm relação direta com a resposta inflamatória, neste trabalho foram reunidas informações históricas em relação à periodontite e estudos recentes sobre periodontite crônica, concentrando-se no papel de $P$. gingivalis no início e na progressão da doença.

\section{MÉTODO}

Este trabalho discute o potencial patogênico de $P$. gingivalis na evolução da periodontite crônica. A busca pelos artigos foi feita nas bases de dados PubMed, Bireme e SciELO; optando-se por aspectos históricos e por estudos publicados sobre o tema entre os anos 2000 e 2015; usando os termos "Periodontite Crônica", "Porphyromonas gingivalis" e "Fatores de Virulência" nos idiomas português e inglês.

Duzentos e cinco artigos foram encontrados e vinte e quatro foram selecionados seguindo o critério de inclusão que se caracterizou por relacionar artigos mais recentes, buscando-os de forma retrospectiva a partir do ano de 2015. Também foram incluídos quatro capítulos de livros publicados entre 1999 e 2012.

\section{DOENÇA PERIODONTAL: DOS PRIMÓRDIOS À CLASSIFICAÇÃOO ATUAL}

Ancestrais do homem já sofriam de doenças periodontais. Reabsorções ósseas encontradas em fósseis da era paleolítica (homem de Neanderthal) e em maxilares de múmias egípcias (2000 a.C.) demonstravam algo similar ao que é observado atualmente. Na China antiga (2700 a.C.), o imperador
Hwang-Ti dividiu as doenças bucais em três tipos: "Fong Ya" (estados inflamatórios), "Chong Ya" (cárie dental) e "Ya Kon" (doenças nos tecidos moles circundantes aos dentes com gengivas apresentando mudança de coloração e sangrantes). Hipócrates (Grécia, 460-335 a.C.) relacionou a doença ao cálculo e ao mau odor. ${ }^{(6)}$

O médico árabe Rhazes (850-923) redigiu sobre a mobilidade e supuração dental. Albucasis (9631013) desenvolveu instrumentos para raspagem de cálculo dos dentes, fator relacionado como a causa da doença. No século XVII, Pièrre Fauchard foi pioneiro em diagnóstico e tratamento para a doença periodontal, afirmando que "a periodontite é um tipo de escorbuto que ataca a gengiva, os alvéolos e os dentes"; indicando, no tratamento, o uso de dentifrícios, contenção de dentes e raspagem do cálculo. ${ }^{(6)}$

No século XVIII, foram desenvolvidas, através dos ingleses Hunter e Fox, as primeiras formas de classificação da doença periodontal, havendo a distinção entre acometimento ósseo e gengival. $(6,7)$ Ainda nesse século, o principal nome considerado como referência para a doença periodontal era o de J. M. Riggs, sendo a mesma conhecida como "Doença de RIGGS". Riggs era defensor de uma terapia mais conservadora e desenvolveu o conceito de profilaxia oral. ${ }^{(7)}$

Entre o final do século XVIII e meados do XIX, começaram a surgir publicações que apontavam para a etiologia bacteriana da doença periodontal, relacionando não a um tipo específico de microrganismo, mas a um complexo bacteriano como uma das causas da doença. Até então, os escritos correlacionavam a enfermidade a causas sistêmicas, físicas, irritativas e vícios, como o tabaco. ${ }^{(6,7)}$

Com os avanços dos estudos sobre a doença periodontal, a necessidade de classificação em diversos subtipos foi surgindo, os quais se caracterizam por etiologias diferentes e se manifestam por uma variedade de aspectos clínicos, microbiológicos, patológicos, bioquímicos e imunológicos, ${ }^{(7)}$ sendo então considerada a origem multifatorial da doença periodontal. 
O que sabemos hoje é que, apesar da presença de microrganismos periodontopatogênicos, fatores ambientais e genéticos estão relacionados ao desenvolvimento, à progressão e à maior gravidade, sendo a presença de bactérias patogênicas por si só insuficiente para o surgimento da doença. Condições sistêmicas como distúrbios hormonais, nutrição deficiente, estresse e tabagismo são fatores decisivos para a inflamação e a destruição tecidual. ${ }^{\left({ }^{(8)}\right.}$

Em 1989, a Academia Americana de Periodontia classificou as doenças periodontais em Periodontite do Adulto, Periodontite de Estabelecimento Precoce, Periodontite Associada a Doenças Sistêmicas, Periodontite Ulcerativa Necrosante e Periodontite Refratária. Essa classificação foi mantida por alguns anos até que a necessidade de mudança foi verificada em 1996.(9)

No ano de 1999, em um Workshop Mundial para a Classificação das Doenças e Condições Periodontais, nova classificação foi estabelecida e perdura até hoje. Dentre as mudanças, o termo "Periodontite do adulto" foi alterado para "Periodontite crônica", já que a doença não atingia apenas indivíduos com idade maior que 35 anos. Foram preconizados os termos Periodontite Agressiva, Periodontite como Manifestação de Doenças Sistêmicas, Doenças Periodontais Necrosantes, Abcessos Periodontais, Periodontite Associada à Lesão Endodôntica e Condições e Deformidades Congênitas ou Adquiridas. (9)

\section{ASPECTOS CLÍNICOS DA PERIODONTITE CRÔNICA}

A periodontite crônica pode se desenvolver em resposta ao acúmulo crônico de biofilme e cálculo supra e subgengivais. Sua gravidade está relacionada com a intensidade de agressão influenciada pela interação entre microrganismos no biofilme e sua patogenicidade. (1) Alguns aspectos clínicos são característicos dessa enfermidade, tais como: acúmulo de biofilme subgengival, que é frequentemente associado com formação de cálculo; inflamação gengival; perda de inserção do ligamento periodon- tal; formação de bolsa periodontal; e reabsorção do osso alveolar. A gengiva apresenta-se edemaciada, exibindo alteração de cor que varia de vermelho-pálido a magenta; e sangramento espontâneo ou como resposta à sondagem. Pode ser encontrado exsudato inflamatório relacionado ao fluido gengival e supuração da bolsa periodontal. Há diferentes profundidades de sondagem e a perda óssea pode ser horizontal e vertical, levando à mobilidade dental nos casos mais avançados. ${ }^{(10)}$

O acúmulo de biofilme sobre as superfícies dento-gengivais é considerado o agente iniciador primário na etiologia da periodontite crônica. $\mathrm{O}$ aumento de microrganismos gram-negativos no biofilme subgengival, especificamente de $P$. gingivalis, T. forshytia e T. denticola, que são excepcionalmente patogênicos ao periodonto, é frequentemente associado com perda contínua de inserção e de osso na periodontite crônica. ${ }^{(10)}$

\section{PORPHYROMONAS GINGIVALIS E SEU PAPEL NA PERIODONTITE CRÔNICA: AVANÇOS RECENTES}

A etiologia da doença periodontal considera três grupos de fatores que determinam se a atividade da doença irá ocorrer: a susceptibilidade do hospedeiro, a presença de espécies patogênicas e a ausência das chamadas "bactérias benéficas". ${ }^{11)}$

Mais de 700 espécies bacterianas têm demonstrado potencial para colonização da cavidade oral em um adulto, sendo algumas delas responsáveis por causar enfermidades (cáries, lesões endodônticas e periodontais). ${ }^{(12)}$

A análise dos microrganismos presentes nas bolsas periodontais em indivíduos com periodontite crônica tem demonstrado uma forte correlação entre as espécies pertencentes ao complexo vermelho ( $P$. gingivalis, $T$. forsythia e $T$. denticola) e a doença, sendo $P$. gingivalis a principal responsável pelo início e progressão dessa enfermidade. ${ }^{(2)}$

$P$. gingivalis é uma bactéria gram-negativa produtora de pigmento negro que vem sendo amplamen- 
te relacionada com a doença periodontal, devido aos achados clínicos, biológicos e químicos. ${ }^{(2)}$ Esse microrganismo precisa obter nutrientes a partir do hospedeiro para garantir sua sobrevivência e proliferação, sendo o ferro constituinte do grupamento heme ou da hemina, um dos principais nutrientes utilizados. ${ }^{(13)}$

Estudos sugerem que a inserção e a remoção de $P$. gingivalis modifica significativamente a microbiota oral, aumentando e diminuindo, respectivamente, a quantidade de bactérias nos sítios periodontais, demonstrando que existe uma forte relação cooperativa entre espécies. Tanto a microbiota comensal como a via do complemento são necessários para levar à perda óssea induzida por $P$. gingivalis, já que em ratos "germ-free" ou deficientes em receptores $C_{3}$ a e $C_{5}$ a não se desenvolveu perda óssea após a inoculação da bactéria. ${ }^{(14)}$

$P$. gingivalis consegue penetrar nas células epiteliais das bolsas periodontais, conseguindo evadir dos mecanismos de defesa do hospedeiro. ${ }^{(15)}$ Seus componentes moleculares agem de forma a modular a resposta imunológica do hospedeiro gerando um aumento na liberação de citocinas pró-inflamatórias e metaloproteinases de matriz e alterações nos mecanismos de apoptose de macrófagos e linfócitos $\mathrm{T}$, o que contribui para progressão e manutenção da doença periodontal. ${ }^{(1,16)}$

Alguns fatores de virulência de $P$. gingivalis têm sido identificados, como a cápsula de carboidrato presente em sua superfície externa, que impede a opsonização pelo complemento e inibe a fagocitose e a morte pelos neutrófilos. O lipopolissacarídeo (LPS) é um componente da membrana externa da parede celular de bactérias Gram-negativas que induz dano tecidual no hospedeiro. Através do LPS, $P$. gingivalis induz a produção de citocinas inflamatórias pelo hospedeiro, tais como as interleucinas IL-1 $\beta$, IL-6 e IL-8. Essa reação leva à destruição do tecido periodontal e à reabsorção de osso alveolar. ${ }^{(4)}$

Consideradas também importantes fatores de virulência na doença periodontal, as gingipaínas, cisteína proteinases de $P$. gingivalis, têm a capacidade de degradar proteínas do hospedeiro e desregular sua resposta imune.(17) Além disso, sua atividade proteolítica favorece a maturação de proteínas de superfície de $P$. gingivalis, importantes para a bactéria se estabelecer, reproduzir, invadir o periodonto(5) e se aderir às células epiteliais.(15) Adicionalmente, elas exercem um importante papel no controle da expressão de fatores de virulência e na estabilidade e/ou processamento de proteínas extracelulares e de superfície. ${ }^{(18)}$

Outro fator de virulência relevante, a sialidase (neuraminidase) é secretada por bactérias patogênicas, incluindo $P$. gingivalis, para a captação de ácidos siálicos de sialoglicoconjugados do hospedeiro, como proteínas salivares. Além de serem nutrientes, os ácidos siálicos são incorporados à estrutura bacteriana, ajudando a mimetizar a célula hospedeira e confundindo a resposta imune. Os periodontopatógenos utilizam a glicosilação (sialilação) de suas proteínas para colonização e evasão da resposta imune, persistindo no hospedeiro. Além disso, a sialidase influencia outros fatores de virulência de $P$. gingivalis, pois a sialilação é uma das etapas da glicosilação, a qual modifica proteínas e regula sua atividade. ${ }^{(19,20)}$

As bactérias existentes no biofilme vivem em ambientes sob limitação de nutrientes, com restrição de ferro livre ou heme. A captação do ferro, tais como heme e protoporfirina IX, é um importante mecanismo pelo qual $P$. gingivalis e outras bactérias obtêm o nutriente para sua sobrevivência e estabilização na infecção. O heme da hemoglobina é a fonte principal deste fator de crescimento no sulco gengival. ${ }^{(21)}$ Outra forma de suplementação é pelo sequestro de ferro-porfirina de proteínas do hospedeiro, como hemopexina, haptoglobina e soro albumina. ${ }^{(22)}$ Os níveis de hemina na cavidade bucal são variáveis. O sangramento como resultado do processo inflamatório gengival eleva as concentrações de hemina subgengivais e pode ser um fator que predispõe ao acúmulo de $P$. gingivalis no sítio. ${ }^{(23)}$

No caso de $P$. gingivalis, um dos sistemas de aquisição do heme é através das proteínas HmuR e HmuY.(24) HmuY é uma lipoproteína heme-ligante 
associada com a membrana externa da célula bacteriana. Tem-se relatado que HmuY é funcional sob a forma de dímeros/tetrâmeros. O dímero HmuY capta o heme e isso o leva à tetramerização sob oclusão dos sítios heme-ligantes. Assim, o tetrâmero HmuY pode proteger o heme do hospedeiro e entregá-lo ao HmuR. Uma vez ligado ao HmuR, o heme é translocado através da membrana externa pelo periplasma e ainda requer a presença de proteínas de ligação para a escolta através do periplasma para o citoplasma. HmuY, na forma associada à membrana externa, pode alojar o heme e proteger a célula bacteriana de danos induzidos pelo heme livre, ${ }^{(25)}$ capaz de catalisar formação de radicais livres. ${ }^{(26)}$

HmuY exerce um importante papel não somente na aquisição do heme mas também no acúmulo de biofilme em superfícies abióticas. Foi demonstrado que a expressão da proteína HmuY é aumentada em condições de baixa concentração de ferro/heme e, nessas condições, observou-se o maior acúmulo de biofilme. Os dados mostraram que HmuY é uma proteína de superfície reconhecível pelo sistema imune durante a periodontite crônica e que a produção de anticorpos anti-HmuY pode inibir a formação de biofilme. ${ }^{25)}$ Anticorpos dirigidos a HmuY reconhecem especificamente essa proteína de $P$. gingivalis mas não reagem com proteínas homólogas de outros periodontopatógenos. ${ }^{(27)}$

Tem sido observado que HmuY consiste num fator de virulência importante, levando à inibição da proliferação celular; indução de apoptose tardia, por estimular a expressão de $\mathrm{Bcl}-2 ;^{(16)}$ e indução de necrose em Células Mononucleares de Sangue Periférico de indivíduos com periodontite crônica. ${ }^{(28)}$

\section{CONSIDERAÇÕES FINAIS}

É um fato que a doença periodontal vem atingindo a população mundial desde seus primórdios evolutivos. Muito foi feito para sua caracterização e para compreensão de sua etiologia como forma de buscar métodos de prevenção e tratamento. ${ }^{(6,7)}$
Com o desenvolvimento de novas tecnologias e refinamento nos exames bioquímicos, hoje compreendemos melhor a doença, definindo sua etiologia como sendo multifatorial, variando em forma e gravidade nos indivíduos acometidos a depender de fatores locais, sistêmicos, genéticos ou ambientais. $^{(8)}$

Apesar da colonização de diversas espécies de microrganismos na cavidade bucal, bactérias do complexo vermelho vêm demonstrando maior associação com a manutenção e o agravamento da periodontite crônica. Dentre elas, $P$. gingivalis é considerada o principal periodontopatógeno ligado à evolução dessa enfermidade ${ }^{(2)}$ por conta de seus mecanismos de evasão e fatores de virulência que agem modulando a resposta imune do hospedeiro, levando à destruição tecidual. ${ }^{(1,14,15,17,27)}$

$\mathrm{O}$ avanço nas pesquisas melhora a compreensão da influência do microbioma oral e dos microrganismos patogênicos, em especial $P$. gingivalis, no processo de instalação e progressão da periodontite crônica. Porém, existe muito a ser descoberto para o entendimento dos complexos mecanismos moleculares que estão envolvidos nessa relação hospedeiro-agente agressor; de forma a se pensar, não só em prevenção, mas em novas formas de tratamento que possam ser associadas aos já existentes e que diminuam o desafio microbiano no hospedeiro, modulando a resposta inflamatória; cooperando para diminuir as perdas provocadas por essa enfermidade, como o edentulismo, o qual gera danos não só físicos, mas também emocionais que, muitas vezes, são irreversíveis para o paciente.

\section{REFERÊNCIAS}

1. Kinane DF, Lindhe J. Patogênese da periodontite. In: Lindhe J. Tratado de periodontia clínica e implantodontia oral. Rio de Janeiro: Guanabara Koogan; 1999. p. 127-50.

2. Farias BC, Souza PRE, Ferreira B, Melo RSA, Machado FB, Gusmão ES, Cimões R. Occurrence of periodontal pathogens among patients with chronic periodontitis. Braz J Microbiol. 2012;909-16. 
3. Herath TDK, Wang Y, Seneviratne CJ, Lu Q, Darveau RP, Wang CY et al. Porphyromonas gingivalis lipopolysaccharide lipide a heterogeneity differentially modulates the expression of IL- 6 and IL- 8 in human gingival fibroblasts. J Clin Periodontol. 2011;38(8):694-701.

4. Trindade SC, Olczak T, Gomes-Filho IS, MouraCosta LF, Cerqueira EMM, Galdino-Neto M. et al. Induction of interleukin IL-1B, IL-1O, IL-8 and immunoglobulin $G$ by Porphyromonas gingivalis HmuY in humans. J Periodont. 2012;47:27-32.

5. Mysak J, Podzimek S, Sommerova P, Lyuya-Mi Y, Bartova J, Janatova T. et al. Porphyromonas gingivalis: major periodontopathic pathogen overview. J Immunol Res. 2014;O1-O8.

6. De Lorenzo JL, Mayer MP. Microbiologia das doenças periodontais. In: De Lorenzo JL. Microbiologia para o estudante de odontologia. São Paulo: Atheneu; 2004. p. 127-50.

7. Shklar G, Carranza FA. The Historical Background of Periodontology. In: Newman MG, Takei H, Klokkevold PR, Carranza FA. Carranza's Clinical Periodontology. 11th ed. St Louis: Elsevier; 2012.

8. Oppermann RV, Weidlich P, Musskopf ML. Periodontal disease and systemic complications. Braz Oral Res. 2012;26(Spec Iss 1):39-47.

9. Dias LZS, Piol SAC, Almeida CSL. Atual classificação das doenças periodontais. UFES Rev. Odontol. 2006;8(2):59-65.

10. Carranza FA, Newman MG, Takei HH. Periodontia clínica. 9a ed. Rio de Janeiro: Guanabara Koogan; 2004.

11. Kesic L, Milasin J, Igic M, Obradovic R. Microbial etiology of periodontal disease - mini review. FU Med Biol. 2008;15(1):1-6.

12. Dewhirst FE, Chen T, Izard J, Paster BJ, Tanner $A C R$ Yu WH. The human oral microbiome. J Bacteriol. 2010;192(19):5002-17.

13. Olczak T, Dixon DW, Genco CA. Binding specificity of the Porphyromonas gingivalis heme and hemoglobin receptor HmuR, gingipain $\mathrm{K}$, and gingipain Rl for heme, porphyrins, and metalloporphyrins. J Bacteriol. 2001;183(19):5599-608.
14. Hajishengallis G, Liang S, Payne MA, Hashim A, Jotwani R, Eskan MA. et al. A low-abundance biofilms species orchestrates inflammatory periodontal disease through the commensal microbiota and the complement pathway. Cell Host Microbe. 2011;10(5):497-506.

15. Olsen I, Progulske-Fox A. Invasion of Porphyromonas gingivalis strains into vascular cells and tissue. J Microbiol. 2015;7:1-9.

16. Carvalho-Filho PC, Trindade SC, Olczak T, Sampaio GP, Oliveira-Neto MG, Santos HA et al. Porphyromonas gingivalis HmuY stimulates expression of $\mathrm{Bcl}-2$ and Fas by human $\mathrm{CD} 3+\mathrm{T}$ cells. BMC Microbiol. 2013;13:200-06.

17. Veith PD, Chen Y, Gorasia DG, Chen D, Gleww MD, O'Brien-Simpson NM et al. Porphyromonas gingivalis outer membrane vesicles exclusively contain outer membrane and periplasmic proteins and carry a cargo enriched with virulence factors. J Proteome res. 2014;13:2420-32.

18. Andrian E, Grenier D, Rouabhia M. Porphyromonas gingivalis - epithelial cell interactions in periodontitis. J Dent Res. 2006;85:392-403.

19. Li C, Kurniyati, Hu B, Bian J, Sun J, Zhang W et al. Abrogation of neuraminidase reduces biofilm formation, capsule biosynthesis, and virulence of Porphyromonas gingivalis. Infection and Immunity. 2012;80(1):3-13.

2O. Stafford G, Roy S, Honma K, Sharma A. Sialic acid, periodontal pathogens and Tannerella forsythia: stick around and enjoy the feast! Mol Oral Microbiol. 2O12;27(1):11-22.

21. Lewis JP, Plata K, Yu F, Rosato A, Anaya C. Transcriptional organization, regulation and role of the Porphyromonas gingivalis W83 Hmu haemin-uptake locus. Microbiol. 2006;152:3367-82.

22. Sroka A, Sztukowska M, Potempa J, Travis J, Genco CA. Degradation of host heme proteins by lysine- and arginine-specific cysteine proteinases (gingipains) of Porphyromonas gingivalis. J Bacteriol. 2001;183(19):5609-16. 
23. Smalley JW, Byrne DP, Birss AJ, Wojtowicz H, Sroka A, Potempa J et al. HmuY haemophore and gingipain proteases constitute a unique syntrophic system of haem acquisition by Porphyromonas gingivalis. PLoS One. 2011;6(2):1-10.

24. Simpson W, Olczak T, Genco CA. Characterization and expression of HmuR, a TonB-dependent hemoglobin receptor of Porphyromonas gingivalis. J Bacteriol. 2000;182(20):5737-48.

25. Olczak T, Wójtowicz H, Ciuraszkiewicz J, Olczak M. Species specificity, surface exposure, protein expression, immunogenicity, and participation in biofilm formation of Porphyromonas gingivalis HmuY. BMC Microbiol. 2O10;1O(134):1-1O.
26. Olczak T, Siudeja K, Olczak M. Purification and initial characterization of a novel Porphyromonas gingivalis Hmuy protein expressed in Escherichia coli and insect cells. Protein Expr Purif. 2006;49:299-306.

27. Śmiga M, Bielecki M, Olczak M, Smalley JW, Olczak T. Anti-HmuY antibodies specifically recognize Porphyromonas gingivalis $\mathrm{HmuY}$ protein but not homologous proteins in other periodontopathogens. PLoS One. 2O15;1O(2):114.

28. Trindade SC, Olczak T, Gomes-Filho IS, MouraCosta LF, Vale VL, Galdino-Neto M et al.

Porphyromonas gingivalis antigens differently participate in the proliferation and cell death of human PBMC. Arch Oral Biol. 2012; 57:314-2O. 